\title{
The Correlation between Macular Ischemia by Fundus Fluorescein Angiography and Spectral Domain Optical Coherence Tomography Findings in Diabetic Macular Edema
}

DINA T. ABDEL-SALAM, M.Sc.; AHMED DAHAB, M.D.; ADEL FATHY, M.D. and KARIM RAAFAT, M.D.

The Department of Ophthalmology, Faculty of Medicine, Cairo University

\begin{abstract}
Background: To study the association between the OCT structural changes, and vascular changes around the fovea in FFA in the detection of ischemic diabetic maculopathy.

Material and Methods: A 35 eyes of 25 patients with ischemic and mixed diabetic maculopathy were included as determined by irregular margins of the FAZ in fluorescein angiography. We measured the best-corrected visual acuity (BCVA), central macular thickness, inner retinal layer thickness and the lateral extent of inner segment-outer segment (ISOS) disruption on SD-OCT images, as well as the FAZ to optic nerve head (FAZ/ONH) area ratio using the Image J program.
\end{abstract}

Results: The central macular thickness and the inner retinal layer thickness showed no significant correlation with FAZ/ONH area ratio ( $p=0.161,0.480$ respectively). The mean horizontal and vertical extents of IS-OS disruption were not significantly correlated with $\mathrm{FAZ} / \mathrm{ONH}$ area ratio $(p=0.630$ and $p=0.732$ respectively. The horizontal and vertical extents of IS-OS disruption showed a significant correlation with Log MAR BCVA ( $r=0.798$ and 0.795 respectively, $p<0.001$ in both). The FAZ/ONH area ratio was positively correlated with LogMAR BCVA but was not statistically significant ( $p=0.815$, $r=0.041)$

Conclusion: In patients with diabetic retinopathy, it is not possible to predict FAZ area based solely on the measurements assessing volume and thickness or retinal structure evaluation on OCT. Consequently, at present OCT cannot replace FA in the detection of ischemic or mixed diabetic maculopathy.

Key Words: Diabetic macular edema-Optical coherence tomography -Fundus Fluorescein Angiography.

\section{Introduction}

DIABETIC macular edema (DME) is a leading cause of visual loss in diabetic patients [1]. In diabetic retinopathy (DR), enlargement of the

Correspondence to: Dr. Dina T. Abdel-Salam, The Department of Ophthalmology, Faculty of Medicine, Cairo University foveal avascular zone (FAZ) is often detected by fluorescein angiography (FA). FAZ enlargement is considered an indication of ischemia and may contribute to macular edema. Macular ischemia is also known to be associated with poor visual outcome in diabetic patients regardless of their treatment [2]

FA plays an important role in identification of ischemic maculopathy. Now optical coherence tomography (OCT) has become popular in diagnosing and staging of DME [3]. Collectively, in the literature, contradictory data is presented on the role of the two imaging methods, OCT and FA, in the detection of ischemic diabetic maculopathy $[4,5,6,7]$

Thus, the purpose of this study was to investigate the correlation between enlargement of the FAZ and structural changes in SD OCT and to determine the factors related to visual outcome in patients with ischemic DME.

\section{Material and Methods}

In this cross-sectional study, the study and data collection conformed to all local laws and were compliant with the principles of declaration of Helsinki. An informed consent was obtained from each participant. Study was conducted in Kasr EL Aini Hospital, Egypt in the period from April 2015 to December 2015. The patients were randomly selected from the outpatient Ophthalmology Clinic.

\section{a- Participants:}

A total of 35 eyes of 25 patients with diabetic macular edema (DME) who underwent fundus fluorescein angiography (FFA) (Topcon TRC50DX, Topcon Medical System Inc., 2015) and spectral-domain optical coherence tomography 
(SD-OCT) (Optovue RTVueTM, Optovue Inc., Fremont, CA) in the study period were included.

Patients with macular edema due to epiretinal membrane or vitreomacular traction and those caused by other diseases such as age related macular degeneration were excluded. Also patients who had undergone laser treatment within the past 6 months or having history of intravitreal anti-VEGF injections within the past 3 months were excluded from the study.

\section{b- Data collection:}

All patients were subjected to full ophthalmological examination of both eyes, including measurement of best corrected visual acuity (BCVA) using a Log MAR chart. FFA images were studied looking for ischemic changes of the macula, enlargement of FAZ and occlusion of perifoveal capillaries. Foveal ischemia was defined as enlargement of the FAZ with irregular margins in the FA.

Considering the variability of the FAZ size and the changes in FAZ size according to refractive error, we used the FAZ/ONH area ratio, calculated by dividing the enlarged FAZ area by the disc area, both measured using Image $\mathbf{J}$ software and the FAZ/ONH area ratio was calculated in each case.

As for SD-OCT, we recorded the central foveal thickness, lateral extent of inner segment-outer segment (IS-OS) disruption in the horizontal and vertical scans, inner retinal layer thickness (measured between the nerve fiber layer and the inner plexiform layer).

The inner retinal layer thickness and horizontal and vertical extent of IS-OS disruption were manually measured at the fovea using a caliper equipped in SD-OCT. The lateral extent of IS-OS disruption was measured within 2000 micrometers from the foveal center in the horizontal and vertical planes.

\section{c-Statistical analysis:}

Data were coded and entered using the statistical package SPSS (Statistical Package for the Social Science) version 22. Data was summarized using mean, standard deviation, median minimum and maximum in quantitative data and using frequency (count) and relative frequency (percentage) for categorical data. Comparisons between quantitative variables were done using the non-parametric Kruskal-Wallis and Mann-Whitney tests (Chan, 2003a). Correlations between quantitative variables were done using Spearman correlation coefficient (Chan, 2003b). $p$-values less than 0.05 were considered as statistically significant.

\section{Results}

The 25 patients in our study included 7 men $(28 \%)$ and 18 women (72\%). The mean best corrected visual acuity (BCVA) of the included subjects was $0.80 \pm 0.43 \mathrm{Log}$ Mar ranging from 0.30 Log to $1.80 \mathrm{Log}$.

Regarding the diabetic retinopathy, 6 (17.1\%) eyes had mild non-proliferative diabetic retinopathy (NPDR), 10 (28.6\%) with moderate NPDR, 5 $(14.3 \%)$ with severe NPDR and $14(40 \%)$ with proliferative diabetic retinopathy (PDR). Among the 35 eyes examined, $6(17.1 \%)$ had no edema, while $6(17.1 \%)$ presented with cystoid macular edema and $23(65.7 \%)$ with diffuse retinal thickening. On the other hand, only 4 (11.4\%) eyes showed sub retinal fluid causing serous neurosensory retinal detachment.

FAZ/ONH area ratio in our patients ranged from 0.35 to 1.10 with a mean value of $0.58 \pm 0.21$. ( 0.16 to 0.4 normal range).

The central macular thickness ranged from 134 to 956 micrometers ( $\mathrm{m}$ ) with a mean value of $333.26 \pm 172.17$ me the other hand, the mean inner retinal layer thickness in the foveal region was $90.83 \pm 34.20$ monging from 40 to 204

Furthermore, 20 eyes (57\%) had no inner segment-outer segment (IS-OS) disruption while 15 (43\%) eyes did have IS-OS disruption. The mean extent of IS-OS disruption within $2000 \mathrm{~m} \mathbf{m o m}$ the fovea in the horizontal plane was 556.20 \pm $800.65 \mathrm{~m}$. While, the mean extent of IS-OS disruption within $2000 \mathrm{~m}$-om the Fovea in the vertical plane was $546.77 \pm 806.01$ maseline characteristics of the studied subjects are shown in Table (1).

Studying the correlation between the FAZ/ONH area ratio and the central macular thickness showed that the correlation coefficient $(r)$ was -0.242 but $p$-value was statistically insignificant with a value 0.161 (Figs. 1,2). Similarly, even though the extent of IS-OS disruption in the horizontal and vertical scans had positive correlation with the FAZ/ONH area ratio ( $r=0.084$ and 0.060$)$ respectively but the results was not statistically significant $(p=0.630$ and $p=0.732$ ) respectively.

Considering different types of macular edema, the mean FAZ/ONH area ratio was $0.63 \pm 0.27$ (ranging between 0.35 and 0.96 ) in cystoid macular edema and $0.51 \pm 0.15$ (ranging between 0.35 and 0.86 ) in diffuse retinal thickening. There was 
significant correlation between the type of edema and the FAZ/ONH area ratio $(p=0.039)$ (Fig. 3$)$.

On the other hand, no significant correlation was found between the presence of sub retinal fluid by OCT and FAZ/ONH area ratio by FFA ( $p=$ $0.775)$. The mean FAZ/ONH area ratio in the presence of sub retinal fluid was $0.58 \pm 0.15$ (ranging between 0.37 and 0.70 ).

There was strong correlation between the type of macular edema and the BCVA $(p=0.019)$. BCVA was greater in diffuse retinal edema with a mean value of $0.67 \pm 0.27$ (ranging from 0.30 and 1.30) than in cystoid retinal edema with a mean value of $1.26 \pm 0.43$ (ranging from 0.80 to 1.80 ) (Fig. 4).

Regarding the inner retinal layer thickness in the foveal region, despite the fact that it showed a positive correlation with the $\mathrm{FAZ/ONH}$ area ratio $(r=0.123)$, the results did not reach statistical significance $(p=0.480)$. On the other hand, no significant correlation was found between the inner retinal layer thickness in the foveal region and the $\operatorname{BCVA}(r=-.072, p=0.682)$.

In another aspect, the central macular thickness showed a highly significant positive correlation with the BCVA ( $r=0.457, p=0.006$ ) (Fig. 5). Similarly, the horizontal and vertical IS-OS disruption showed a significant strong positive correlation with poor visual acuity ( $r=0.798$ and 0.795 respectively, $p<0.001$ in both) (Figs. 6,7).

Finally, even though the FAZ/ONH area ratio showed a positive correlation with the BCVA in Log Mar ( $r=-0.041)$ but the results showed no statistical significance $(p=0.815)$.
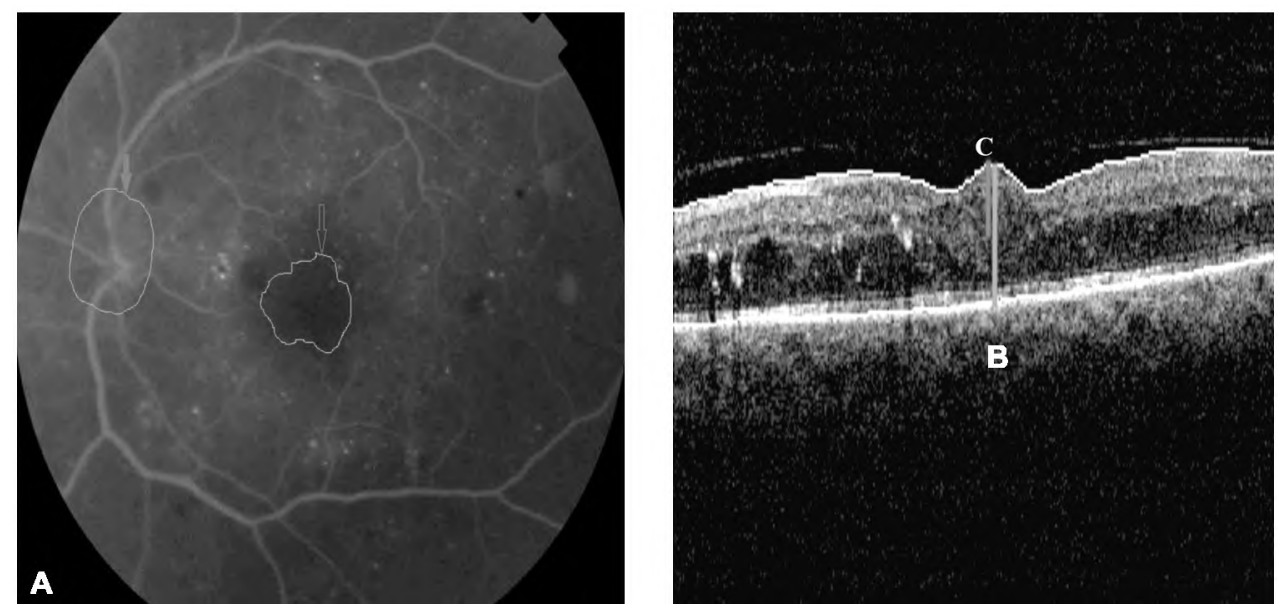

Fig. (1): FA and SD-OCT measurements of patient with ischemic diabetic macular edema. (A) The area of FAZ enlargement (empty arrow) and the disc (solid arrow) were measured using Image $\mathbf{J}$ software. The FAZ/ONH area ratio was 0.7 in this patient. (B) The central macular thickness (green line) was 390 (c) The inner retinal layer thickness measured between outer nerve fiber layer \& the inner plexiform layer (red line) was 204 m
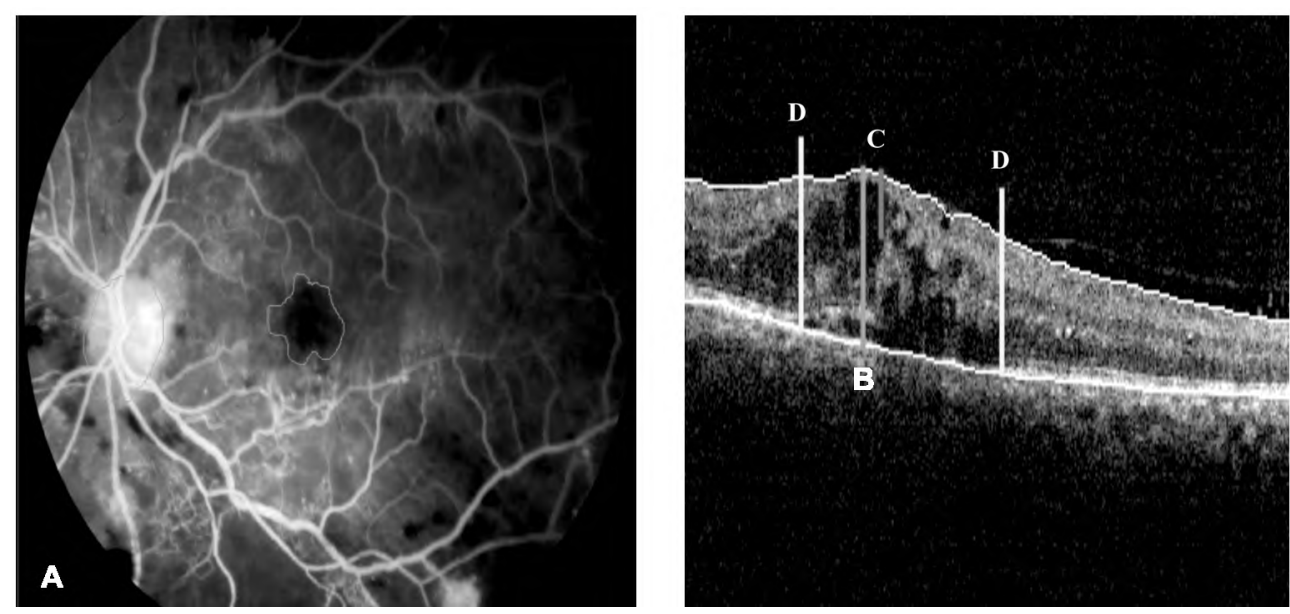

Fig. (2): FFA and SD-OCT measurements of patient with ischemic diabetic macular edema. (A) The FAZ/ONH area ratio was 0.5. (B) The central macular thickness (green line) was 573 (C) The inner retinal layer thickness (red line) was 320 m.(D) The lateral extent of IS/OS disruption (the distance between the two yellow lines) was 805 me 


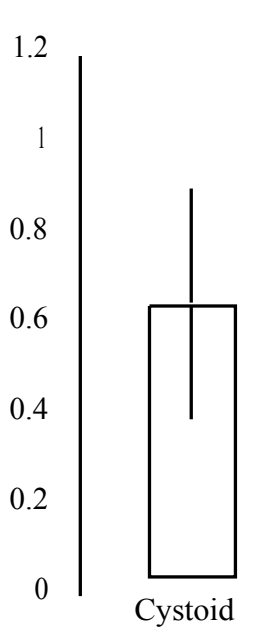

$p=0.039$

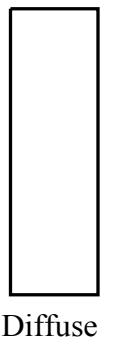

Type of Edema

Fig. (3): Relation between FAZ/ONH and type of macular edema in OCT

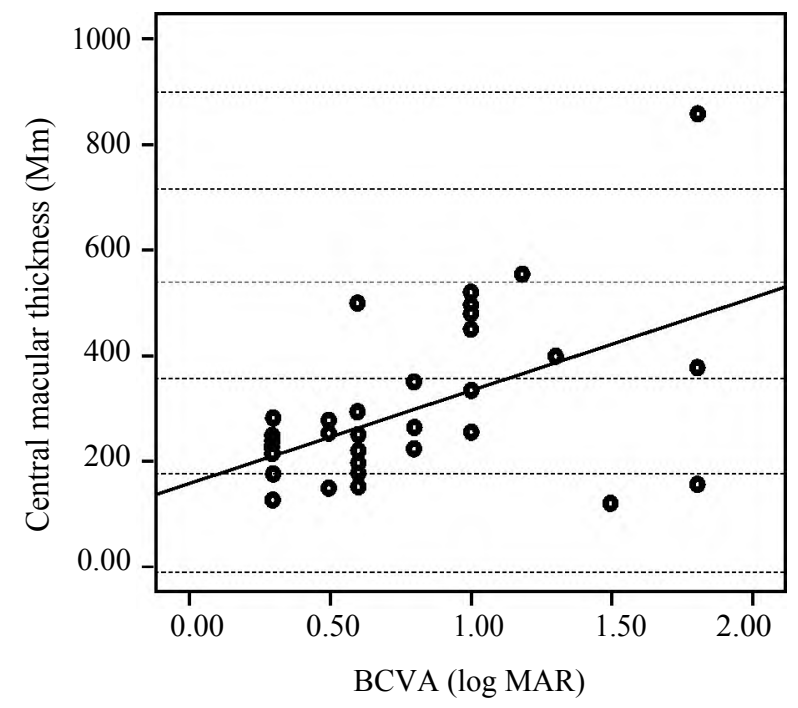

Fig. (5): Relation between the central macular thickness and the BCVA in Log Mar.

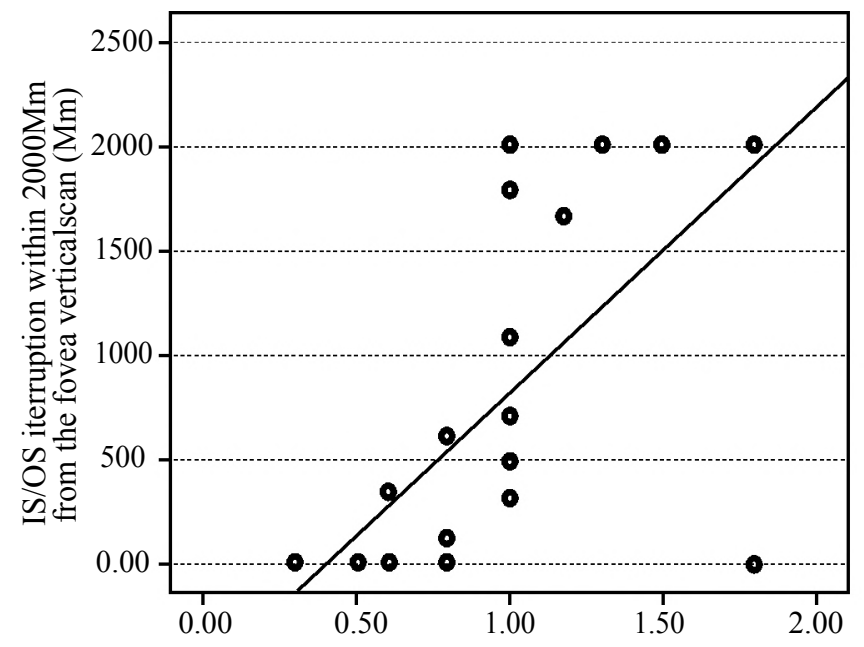

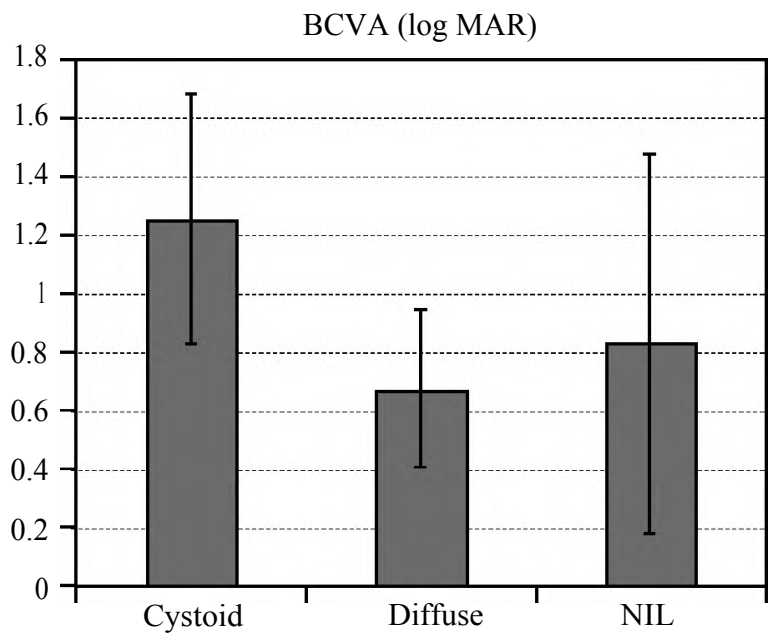

Type of Edema

Fig. (4): Relation between BCVA in Log Mar and the type of macular edema in OCT.

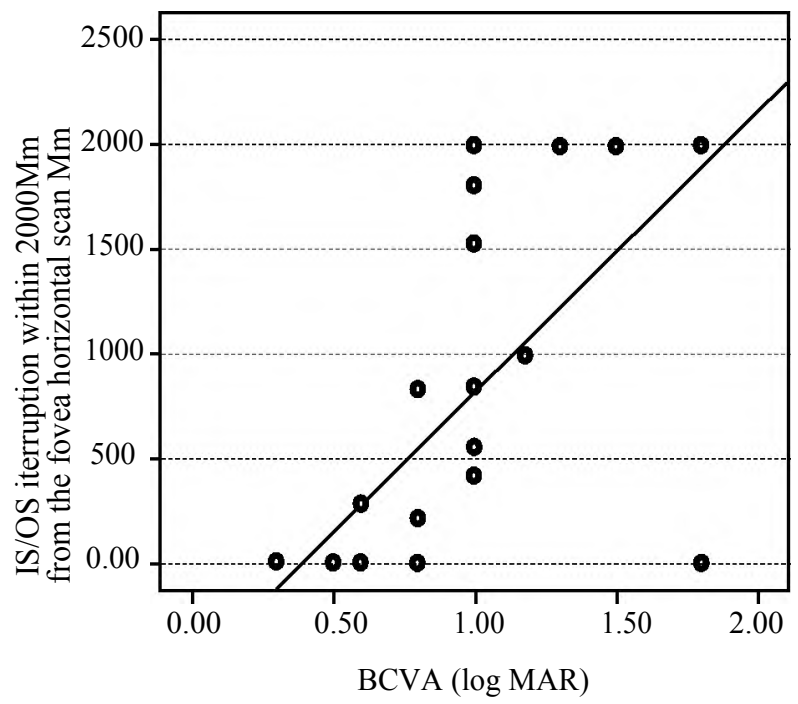

Fig. (6): Relation between IS/OS disruption within 2000 micrometers from the center of the fovea in the horizontal scan and the BCVA in Log Mar.

Fig. (7): Relation between IS/OS within 2000 micrometers from the center of the fovea in the vertical scan and the BCVA in Log Mar. 
Table (1): Baseline characteristics of studied subjects.

\begin{tabular}{|c|c|}
\hline Age (years), mean $\pm \mathrm{SD}$ & $56.51 \pm 8.68$ \\
\hline $\begin{array}{l}\text { Sex, no }(\%): \\
\text { Female } \\
\text { Male }\end{array}$ & $\begin{array}{l}25(71.4) \\
10(28.6)\end{array}$ \\
\hline $\begin{array}{l}\text { Type of diabetes, no }(\%) \text { : } \\
\text { Type I } \\
\text { Type II }\end{array}$ & $\begin{array}{l}1(2.9) \\
34(97.1)\end{array}$ \\
\hline Duration of diabetes (years), mean $\pm \mathrm{SD}$ & $14.57 \pm 4.71$ \\
\hline $\begin{array}{l}\text { Lens, no }(\%) \text { : } \\
\quad \text { Phakic } \\
\text { Pseudophakic }\end{array}$ & $\begin{array}{l}28(80.0) \\
7(20.0)\end{array}$ \\
\hline $\begin{array}{l}\text { BCVA }(\log \text { MAR }), \text { mean } \pm \text { SD } \\
\mathrm{IOP}(\mathrm{mmHg}), \text { mean } \pm \mathrm{SD}\end{array}$ & $\begin{array}{l}0.80 \pm 0.43 \\
14.14 \pm 2.22\end{array}$ \\
\hline $\begin{array}{l}\text { Fundus examination, no (\%): } \\
\text { Mild NPDR } \\
\text { Moderate NPDR } \\
\text { Severe NPDR } \\
\text { PDR }\end{array}$ & $\begin{array}{l}6(17.1) \\
10(28.6) \\
5(14.3) \\
14(40.0)\end{array}$ \\
\hline $\begin{array}{l}\text { Type of Edema, no }(\%) \text { : } \\
\text { Cystoid } \\
\text { Diffuse } \\
\text { None }\end{array}$ & $\begin{array}{l}6(17.1) \\
23(65.7) \\
6(17.1)\end{array}$ \\
\hline $\begin{array}{l}\text { Presence of sub retinal fluids, no (\%): } \\
\text { Present } \\
\text { Absent }\end{array}$ & $\begin{array}{l}4(11.4) \\
31(88.6)\end{array}$ \\
\hline $\mathrm{FAZ} / \mathrm{ONH}$ ratio, mean $\pm \mathrm{SD}$ & $0.58 \pm 0.21$ \\
\hline $\begin{array}{l}\text { Central macular thickness } \\
\quad(\mu \mathrm{m}), \text { mean } \pm \mathrm{SD}\end{array}$ & $333.26 \pm 172.17$ \\
\hline $\begin{array}{l}\text { Inner retinal layer thickness in the } \\
\text { foveal region }(\mu \mathrm{m}), \text { mean } \pm \mathrm{SD}\end{array}$ & $90.83 \pm 34.20$ \\
\hline $\begin{array}{l}\text { IS/OS interruption within } 2000 \mu \mathrm{m} \text { from the } \\
\text { fovea horizontal scan }(\mu \mathrm{m}), \text { mean } \pm \text { SD }\end{array}$ & $556.20 \pm 800.65$ \\
\hline $\begin{array}{l}\text { IS/OS interruption within } 2000 \mu \mathrm{m} \text { from the } \\
\text { fovea vertical scan }(\mu \mathrm{m}), \text { mean } \pm \text { SD }\end{array}$ & $546.77 \pm 806.01$ \\
\hline
\end{tabular}

\section{Discussion}

FAZ enlargement is known to occur in patients with diabetic retinopathy, although the FAZ area varies considerably in normal study subjects [2] Despite this variability, FA remains the gold standard for evaluating the retinal perfusion status and for detecting macular ischemia in patients with diabetic retinopathy $[8]$. Recent advances in imaging have made it possible to analyze morphological changes of the retina in various retinal diseases. Optical coherence tomography (OCT) is an important tool being used to evaluate the retinal status and to predict the visual outcome.

To test this correlation, we analyzed the data of 35 eyes of 25 patients with DME who had underwent FA and Spectral-domain OCT. According to our results, no significant correlation was found between the thickness of the inner retina and central macular thickness detected by OCT and FAZ/ONH ratio detected by FFA ( $p=0.480$, $p=0.161$ respectively). A similar result was found by Dmuchowska et al., [4] and Ozdek et al., [5] .

The chronic ischemic changes could theoretically lead to atrophy and result in reduced thickness. On the other hand, these changes might be compensated by edematous enlargement of glial cells, as explained by Fine \& Brucker [9]. Another possible explanation is that most of the cells in the area of perifoveal hypo-and non-perfusion survive, though in a semi-starved state. This hypothesis cannot be proved based on the currently available OCT images, as their resolution does not allow us to count individual cells. In contrary, loss of inner retinal layers on OCT was found to be highly correlated with capillary non-perfusion on FA $(r=0.953 ; p<0.001)$ in a study done by Yeung et al., including 59 eyes from 59 patients with DME in Taiwan [10].

This discordance appears to be related to the duration of ischemia, which may induce macular edema especially with inner retinal layer thickening by increasing capillary permeability in earlier periods of ischemia. However, longstanding ischemia seems to cause atrophy of retinal tissue and reduction of the foveal volume in later disease, which can lead to severe visual loss.

We furtherly tried to find association between the visual acuity with other parameters, and the results showed significant correlation between the BCVA in Log Mar and the central macular thickness which was comparable to the results reached by Alasil et al., [6]

Similarly, Otani et al. reported that OCT images of 59 eyes of 42 patients showed three basic types of macular edema: Sponge-like retinal swelling (88\%), CME (47\%) and serous retinal detachment $(15 \%)$. They studied patients with CSME and CME, and reported a significant intermediate negative correlation between the visual acuity and central retinal thickness regardless of the different tomographic features $(r=0.61, p<0.001)$ [7] .

In our study, we detected serous retinal detachment on OCT as an optically hypo-reflective space between the outer layer of the retina and the retinal pigment epithelial layer in $14 \%$ in our study group. In addition to that, significant correlation was found between the type of macular edema and the $\operatorname{BCVA}(p=0.019)$ but no significant correlation was found between the BCVA and the FAZ/ONH ratio by FFA. 
Our study had several limitations, including its small sample size and its retrospective nature. There are also confounding factors that contribute to the ischemic status, such as previous laser treatment, anti-VEGF injection, and the duration of the edema. Further studies in which these confounding variables are considered will be required.

FA is known to be a sensitive method for the qualitative assessment of fluid leakage in diabetic macular edema. Furthermore, FA is an invasive test and the information it provides is qualitative and the interpretation of the results may be subjective. On the other hand, OCT is noninvasive, comfortable, safe and fast and can be repeated as often as is required and offers an alternative to the FA in the follow-up of changes in retinal thickness after laser photocoagulation and intravitreal steroid injections. However, FA is still essential for the assessment of the foveal perfusion state which cannot be demonstrated with OCT. After an initial FA, OCT seems to be a useful noninvasive tool in the close follow-up of the effectiveness of treatment modalities in diabetic maculopathy.

Now, it seems that OCT cannot replace FA in assessing diabetic ischemic maculopathy. FA enables the evaluation of foveal perfusion, which according to our study, could not be predicted based on OCT.

\section{References}

1- GAUDRIC A., MASSIN-KOROBELNIK P., et al.: Diabetic maculopathy classification, epidemiology, spontaneous outcome, treatment. Diabëte \& Mëtabolisme, 19 (5): 422-9, 1993.

2- ARENDB O., WOLFB S.B., JUNG F., et al.: Retinal microcirculation in patients with diabetes mellitus: Dy- namic and morphological analysis of perifoveal capillary network. British Journal of Ophthalmology, 75: 514-518, 1991.

3- BYEON S.H., CHU Y.K., HONG Y.T., et al.: New insights into the patho anatomy of diabetic macular edema: angiographic patterns and optical coherence tomography. Retina. (Philadelphia, Pa.), 32 (6): 1087-99, 2012.

4- DMUCHOWSKA D.A., KRASNICKI P., MARIAK Z., et al.: Can optical coherence tomography replace fluorescein angiography in detection of ischemic diabetic maculopathy? Graefe's Archive for Clinical and Experimental Ophthalmology, 252 (5): 731-738, 2014.

5- OZDEK S.C., ERDINÇ M.A., GÜRELIK G., et al.: Optical coherence tomographic assessment of diabetic macular edema: Comparison with fluorescein angiographic and clinical findings. Ophthalmologica. Journal International D'ophtalmologie. International Journal of Ophthalmology. Zeitschrift Für Augenheilkunde, 219 (2): 86-92, 2005.

6- ALASIL T., KEANE P.A., UPDIKE J.F., et al.: Relationship between optical coherence tomography retinal parameters and visual acuity in diabetic macular edema. Ophthalmology, 117 (12): 2379-86, 2010.

7- OTANI T., KISHI S., MARUYAMA Y., et al.: Patterns of diabetic macular edema with optical coherence tomography. American Journal of Ophthalmology, 127 (6): 688693, 1991.

8- CONRATH J., VALAT O., GIORGI R., et al.: Semiautomated detection of the foveal avascular zone in fluorescein angiograms in diabetes mellitus. Clinical and Experimental Ophthalmology, 34 (2): 119-123, 2006.

9- FINE B.S., BRUCKER A.J., et al.: Macular edema and cystoid macular edema. American Journal of Ophthalmology, 92 (4): 466-81, 1981.

10- YEUNG L., LIMA V.C., GARCIA P., LANDA G. and ROSEN R.B.: Correlation between spectral domain optical coherence tomography findings and fluorescein angiography patterns in diabetic macular edema. Ophthalmology, 116 (6): 1158-1167, 2009 


\section{العلاقة بين قصور الدورة الد موية بالماقولة فى حالات إعتلال

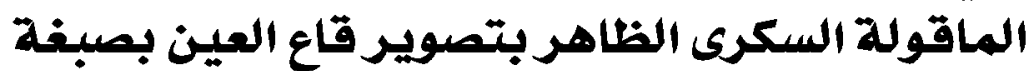

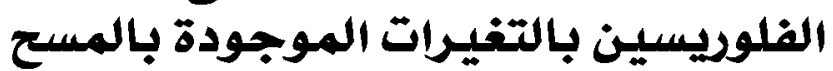

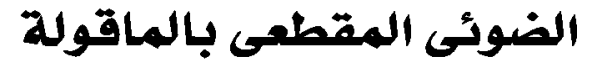

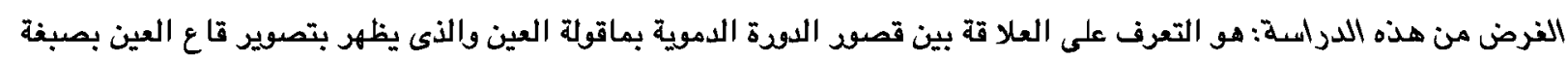

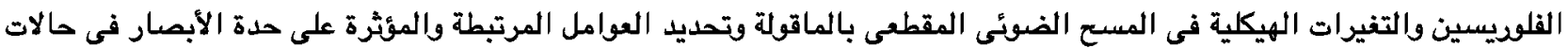

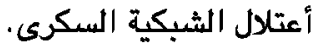

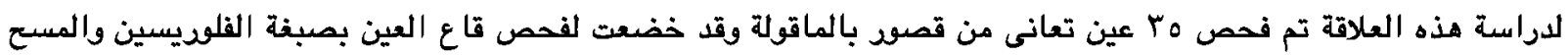
الضوئى المقطعى وتم حساب العلاقة بين منطقة قصورالدودة الدموية بالماقولة وحجم العصب البصرى الظاهر بتصوير قاع العين بصبغة الفلويسين.

أما بالنسبة للمسح الضوئى المقطعى فقد سجلنا سمك الماقولة المركزى وكذلك سمك الطبقة الداخلية للشبكة ودراسة شكل الطبقة الخارجية للشبكية وذلك لتحديد دود ومعرفة قدرة المسع الضوئى المقطعى فى الكثف عن قصور الدودة الدموية بالماقولة كشفت

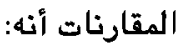
- لا توجد علاقة ذات دلالة احصائية بين حجم منطقة تصور الدورة الدموية بالماقولة وسمك الماقولة المركزى وكذلك سمك الطبقة

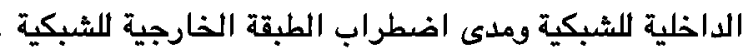

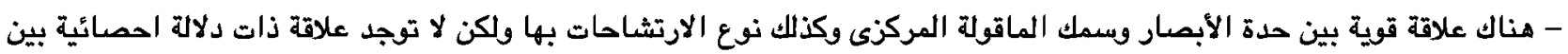

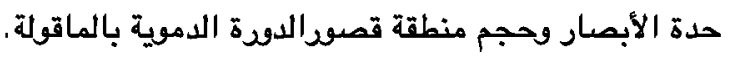
لم تقدم دراستنا إجابة شافية لهذه المسئلة ومع ذلك فى الوقت الحاضر يبدو المسيح الضوئى المقطعى لا يمكن ان يحل محل التصوير بصبغة الفلويسين فى هذا الصدد . 